\title{
Factors That Influence Anti-Retroviral Therapy Adherence among Women in Lilongwe Urban Health Centres, Malawi*
}

\author{
Noel Dzimnenani Mbirimtengerenji ${ }^{1}$, Getrude Jere ${ }^{1}$, Shyle Lengu ${ }^{2}$, Alfred Maluwa ${ }^{2}$ \\ ${ }^{1}$ Kamuzu College of Nursing, Lilongwe, Malawi; ${ }^{2}$ Kamuzu Central Hospital, Lilongwe, Malawi. \\ Email: ndmbiri@hotmail.com,ndmbiri@kcn.unima.mw, ndmbiri5@gmail.com
}

Received December $19^{\text {th }}, 2012$; revised February $16^{\text {th }}, 2013$; accepted February $28^{\text {th }}, 2013$

\begin{abstract}
Introduction: Sub-Saharan Africa remains most severely affected, with nearly 1 in every 20 adults (4.9\%) living with HIV and this is accounting for $69 \%$ of the people worldwide. Although the regional prevalence of HIV infection is nearly 25 times higher in sub-Saharan Africa than in Asia, almost 5 million people are living with HIV in South, South-East and East Asia combined. Purpose: The purpose of this study was to find out the factors that influence anti-retroviral therapy adherence among women in Lilongwe Urban, Malawi. Methods: A descriptive cross-sectional design was used to study multi sites using quantitative methods. The sites were ART clinics at Area 18 health centre, and Area 25 health centre. A questionnaire was used to a convenient sample of $118 \mathrm{HIV}$ positive women. Quantitative data from close-ended questions were coded and analyzed using the Statistical Package for Social Science (SPSS), version 16. Logistic regression model was used to execute the potential covariates. Findings: ART adherence among women is influenced by knowledge levels on: perceived importance and consequences for not adhering to ART; Short waiting time; good relationships with the next of kin and service providers; trust and effective coping mechanisms to stressful events. Source of information was highly associated with adherence in the logistic regression OR $\leq 2.89$; CI ( $1.66 \pm$ 5.38); $p$ (0.039). Moreover, Short waiting time of the women at the hospital during the ARV refill period is highly associated with ART adherence level OR $\leq 4.11$; CI $(2.05 \pm 6.12) ; \mathrm{p}(0.021)$. On the other hand, factors that contribute to non-adherence are reduced knowledge level p-0.002; Side effects of ART; bad relationships with service providers and relationship with the next of kin as well as occupation of the clients (women). Conclusion: Despite stressful events to HIV positive living women, this study revealed that the majority of these participants would continue taking ART if the factors are very minimal. Encouraging the women who stop taking ART particularly in urban health centres due to such factors like religious beliefs that God is superior and will heal them would influence the ART survival rate in Malawi.
\end{abstract}

Keywords: ARV Adherence; Anti-Retroviral Therapy; Urban Health Centres

\section{Introduction}

AIDS is one of the greatest public health and social problems threatening the human race in the world. The greatest burden of the HIV/AIDS pandemic is in subSaharan Africa. According to the Joint UN Committee on HIV/AIDS [1,2], an estimated 36 million people worldwide were living with HIV, of which 7 million were newly infected $[3,4]$. Sub-Saharan Africa remains most severely affected, with nearly 1 in every 20 adults (4.9\%) living with HIV and this is accounting for $69 \%$ of the people that are living with HIV worldwide. Although the regional prevalence of HIV infection is nearly 25 times higher in sub-Saharan Africa than in Asia, almost 5 million people are living with HIV in South, South-East and

${ }^{*}$ Conflict of Interest: Non.
East Asia combined. After sub-Saharan Africa, the regions most heavily affected are the Caribbean and Eastern Europe and Central Asia, where 1.0\% of adults were living with HIV in 2011.

Combination of ART, previously known as Highly Active Antiretroviral Therapy (HAART) has dramatically improved the survival of patients living with HIV \& AIDS in industrialized countries of the world, but the availability of these ARVs in the developing countries is still limited. Access to ART is an important element of strategy to support people living with HIV and AIDS as well as preventing transmission of infection [5]. By reducing the viral load, ARV drugs may, reduce the risk of HIV sexual transmission. Sick people can be able to return to work. Parents can stay alive longer, thus delaying the time when children become orphans. 
In Malawi, at the beginning of 2004, there were nine facilities in the public sector delivering ART, and estimated 3000 - 4000 patients on treatment. In 2005, it was estimated that 185,000 people were in immediate need of ART. Because of this immediate need, a major scale up of ART was planned. 60 hospitals and clinics in the public sector were selected for ART scale up providing broad geographical coverage throughout Malawi. Therefore, more than 340,000 people were on treatment in 2008. ART is provided free of charge in the public sector in Malawi [5]. This Government controlled program is currently influencing people to seek for treatment of which by 2012 all admitting hospitals and health centres, both for the government and Mission facilities, were distributing the ARVs in the country.

Scale up in the new facility involved the use of first line ART regimen only (Triomune-Stavudine, Lamivudine and Nevirapine), but when health facilities showed capacity to properly deliver such treatment, they were to be provided with alternative first line and second line therapy. A five-year plan for ART (2006-2010) was then developed and approved by the $\mathrm{MOH}$ and its stakeholders [6]. Malawi's inspirational goal was to provide universal access of ART by 2010 [6]. Fulfillment of this goal means having 170,000 patients on treatment and each year increasing this number of patients becoming eligible for ART. i.e. (90,000 new patients per year).

\section{Concept of Adherence}

Dose adherence refers to the number and proportion of doses taken; schedule adherence refers to adherence to doses taken on time; and dietary adherence refers to doses taken correctly with food [7]. Adherence and nonadherence in Malawi is measured using various methods. These include direct observation, blood drug concentration, electronic monitoring, pharmacy report, self-reporting 1 - 4 days, biomedical markers such as CD4+ count and viral level as well as adherence to clinical report (White et al. 2008).

In Malawi more especially in urban health centres like Kawale, Area 18 and Area 25 in Lilongwe city, adherence is measured by pill count, pharmacy refill, not missing appointments and reviewing the master cards of patients. In this city where the HIV prevalence rate is $11.2 \%$, adherence to ART is crucial. According to the records of Kawale health centre [8], ART clinic, the total number of patients accessing ART services from June 2005 to June 2010 was 2242. One thousand one hundred and forty two (1142) clients out of the total number were female non-pregnant, 260 clients were pregnant women and 724 clients were males. This indicated that $63 \%$ of females were accessing ART at this health centre and
47\% males were accessing ART services. 980 (44\%) clients out of the total number were adhering to ART and $1262(66 \%)$ clients were not adhering to ART [9]. Therefore, there was a need to find out factors contributing to ART adherence and non-adherence among women in Malawi. The significance of this study to the Malawi nation was to determine the women adherence level which would help to ensure viral suppression, decrease the risk of disease progression and drug resistance.

Moreover, at Area 18 health centre in the same Lilongwe City, the total number of clients enrolled for ART from 2006 to March 2010 was 1150 . Seven hundred and eighteen (718) clients were females while 432 clients were males. This then indicated that $62.4 \%$ females were having the ARV and $47.6 \%$ males were also on therapy [10]. Three hundred and thirty clients (330) had adverse outcomes (died, defaulted, stopped and transferred out). This data shows that there are more women accessing ART than men and non-adherence and adherence were not clear in this clinic. Therefore, there was need to find out the factors contributing to this non-adherence and adherence among the women.

Data from Area 25 health centre also indicated that there are more female clients accessing ART than male clients. According to the records from January to June 2010, 352 clients accessed ART services. Out the total clients accessing ART services, 234 (66.5\%) were females and the rest were males (43.5\%) [10]. This can also means that more females may adhere or non-adhere. Limited studies had scientifically expounded those factors that influence adherence and non-adherence to ART among women in Malawi.

The main objective of this study was to explore factors that contribute to ART adherence and non-adherence among women. For this to be done we came up with the specific objectives that focused on assessing perceived knowledge of ART adherence among women taking ART in two of Lilongwe urban health centers. We also determined the modifying physiological factors contributing to ART adherence and non-adherence among women taking ART. We lastly also analyzed modifying psychosocial factors contributing to ART adherence and nonadherence among women taking ART.

These objectives were based on the following research questions like; what were the level of knowledge on ART adherence and non-adherence among women taking ART? What modifying physiological factors contributed to ART adherence and non-adherence among women on ART in the urban areas? And we also questioned the modifying psychosocial factors that contribute to ART adherence and non-adherence among women on ART?

This research was based on Health Belief Model which entails that women's individual perception on HIV 
and AIDS is influenced by the physiological factors and psycho-sociological factors. The women's likelihood action would be determined by the pandemic's seriousness and perceived threats. The likelihood actions of women like seeking medical care would be influenced by social amenities that surround them like mass media HIV programs, frequent radio HIV advertisements, television comedies and close relative HIV infected serious illness or death [11]. Furthermore, women particularly in Malawi, believe that perceived benefits of preventive action must not outweigh the perceived barriers to preventive health action.

\section{Methodology}

We used a descriptive cross-sectional quantitative design. Descriptive study design was chosen as it is a means of describing what exists in research. It also helps to determine the frequency with which something occurs. The purpose of the descriptive research is the exploration and description of the phenomena in real life situations (Burns \& Groove, 2005). In a cross-sectional study, the information is collected from each subject at one point in time.

The setting for data collection was Lilongwe urban health centres. Multi-sites were used which included, Area 18 health centre, and Area 25 health centre. We only focused on ART clinics to collect the data. These areas were natural settings for women on ART as they periodically go and seek advice on HIV positive living and collect ARVs. Therefore, we did not manipulate the setting of the study, so as to have a strong research validity and reliability. A convenient sample of 118 participants was used. In a convenient sampling, available subjects were simply entered into the study until the desired sample size was reached [12]. All clients who were registered at the clinics mentioned above and were on ART participated in the study.

The inclusion criteria (see Figure 1) also involved only women who were HIV positive and had come for ART services at the clinics with more than three years on therapy. These were only women who had been using Area 18 and Area 25 health centres for their ART clinics. Only women who were above 18 years of age and had been registered in these clinics were involved. All clients or women who were new at these clinics were not involved in this study. Women who were on ART less than three years were not included as they were considered not to have more experience to determine the adherence factors. Women who were transferred in the clinic from other clinics although they were more than three years on ART were excluded from participating in this study. These inclusion and exclusion criteria were strictly followed to reduce the selection bias and enhance the validity

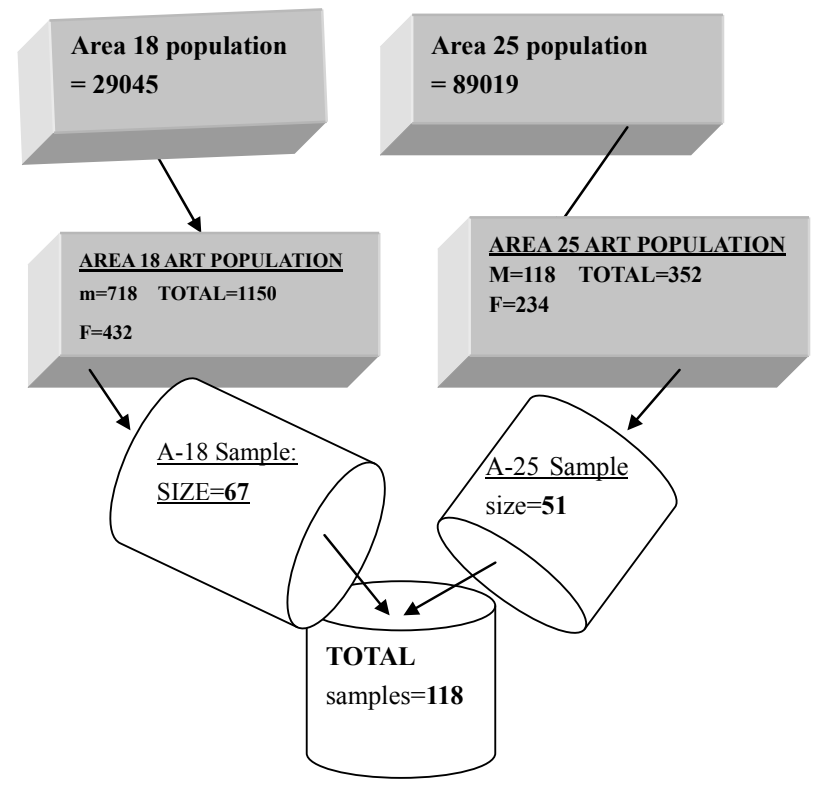

Figure 1. Distribution of the sample size for Area 18 and Area 25 health centres.

of the data.

Data was collected using a highly structured questionnaire with closed ended questions. Closed ended questions helped to provide direct quantitative unbiased data. Such questionnaire elicited $100 \%$ response rate and had an added advantage in their ability to produce no missing data. The researchers interviewed the participants strictly on face to face in avoidance of recall bias.

We strengthened the content validity of this study by piloting the questionnaire in another area. So, data collection tool was tested on similar participants at Mchinji District Hospital, ART clinic which is more than 50 kilometers from Lilongwe city, but has the same Chewa tribe of people. Moreover, we controlled a lot of confounders in this study by proper participants' selection and clearly matching the dependent and independent variables [13]. Use of multivariate and logistic regression intensified our confounding control.

We also sought permission from Lilongwe District Health Officer who looks into the affairs of the selected ART health centres which were, Area 18 and Area 25 health centres. Convenient sample of 118 participants were assessed on factors contributing to ART adherence and non-adherence from the two urban health centres in Lilongwe. This means that samples were Area $18(\mathrm{n}=51)$ and Area $25(n=67)$. This sample size $(n)$ was determined based on single population proportion (p) formula.

The following formula [14] was used:

$$
n=\frac{z^{2}(1-p)}{E^{2}}
$$


where $n$ was sample size, $p$ was the proportion of number of HIV women in Lilongwe; and $E^{2}$ was the margin error. We only allowed $5 \%$ for expected margin of error $(E)$ with $95 \%$ confidence interval level. $Z^{2}$ was used as a constant value of 1.96 .

Data was analyzed in order to summarize, organize, interpret and numerically communicate the collected information in inferential statistics. Quantitative data from close-ended questions was coded and analyzed using the Statistical Package for Social Science (SPSS), version 16. We generated tables that showed association on p-value and positive odds ratio after using $95 \%$ as a cut point in the bivariate analysis and logistic regression models [15]. Some numerical data collected were presented in tables after comparing major variables in multivariate analysis.

Consent was sought from the participants before collecting the data by proper explanation and signing their initial names beside the data collector. In order to ensure protection of human rights, clear explanation was done to participants on the whole study; its purpose and benefits. The participants were told about their rights to withdraw from the study at any time they wish and that they would not be punished for the decision made. Participants were assured of confidentiality of the data collected, and that no names were written on the questionnaire after interview, instead numbers were used. They were also assured of privacy to information given that the questionnaire were kept in a locked cupboard and be accessed by the researcher and the supervisor only. To minimize client's risks [16], the interviews were carried out for a maximum of 30 minutes. In addition to that, the questions were asked in a way not to embarrass them nor coerce the women.

\section{Results}

The results of this study shows that most women who access ART are in the age ranging from $26-35$ years with a representation of $50 \%(59)=118$. This is followed by those women aged $15-25$ years $21 \%(17)=118$. This strongly suggests that age is one of the contributing factors to ART adherence as only those women that were above 26 - 35 could adhere properly to ART program. The results also indicate that $49 \%(57.6)=118$ of women accessing ART are of Chewa tribe since the data was collected in the central region where most Chewa tribes are found and is dominated by this tribe, this could not have taken as a strong factor.

Most women accessing ART are married (63\%). On education background, the results indicate that most women reached primary school $(45.8 \%)$ followed by those who reached secondary school (24.6\%) and then those who never attended school (22\%). There was strong association between the levels of education to the adherence of the women on ART.

The results indicate that $48.3 \%$ of women earn a living through business. However, the majority of women are not employed, this puts them at risk to HIV and AIDS as some women indulge into extra marital sex for money. Only few women were found to rely on their husbands or other people for financial support (22\%). This is followed by those who do small scale farming and sell their crops to earn a living (17.8\%). On next of kin, $49 \%$ of women stay with their husband followed by $32.2 \%$ of women who stay with their children alone or other relatives and $11 \%$ of women either stay alone or with other related members of their family. Hundred and eleven participants $(93.1 \%)$ reported of not smoking while 5.9\% of women reported of smoking cigarette. On alcohol consumption, $105(89 \%)$ of women do not drink alcohol while $13(11 \%)$ women consume different types of alcohol.

The data also shows that $47.5 \%$ of women who access ART have adequate knowledge that ART can be started to be taken when the immunity is low while the rest $(52 \%)$ have no adequate knowledge on when to start ART. When asked about the source of information, about ART, $91.5 \%$ of the participants answered that they got the information from the medical personnel. The rest got the information from friends $(2.5 \%)$ and through the mass media (5.1\%). This suggests that most of the people get the information from the health care personnel.

When asked about the knowledge level on adherence, $83.1 \%$ of women answered correctly that it means taking drugs at the right time as prescribed by the ART service provider. This suggests that ART non adherence could not be caused by inadequate knowledge level of the clients. However, $12.7 \%$ only concentrated on not becoming sick anyhow as the main factor. The rest (4.2\%) concentrated only on prevention of resistance to ART as the cause of non adherence factor.

When asked whether they adhere to ART or not, 107 $(90.7 \%)$ women said they adhere to ART while 11 (9.3\%) women admitted of not adhering to ART. When asked about how they know that they adhere i.e. indications that they adhere to ART, $24.6 \%$ of women measure adherence by pill count, $35.6 \%$ measure by not becoming sick more often. On the other hand, $22.7 \%$ of participants measure by finishing all the drugs before they go for refill while $15.3 \%$ of women measure adherence by fulfilling appointments. Only $2.5 \%$ of participants measure adherence by CD4 count. This suggests that most of the clients do not know the effective way of adherence.

On indications of non-adherence, it was noted that $45.8 \%$ of the women measure it by frequent illnesses while $22 \%$ measure adherence by pill count. On the other 
hand, $14.4 \%$ of the participants measure non-adherence by skipping days without taking drugs and missing appointments. However, 9.6\% don't understand how to know that they are not adhering to ART. Therefore, it was noted that frequent illness especially the ARV side effects is the major parameter for women's ART adherence.

It was also noted that Christians were mostly adhering to ART (89.6\%) than other denominations. In this analysis selection bias could not be controlled as a result being a Christian did not show much significant to the adherence. This is because the study setting was dominated by the Christians.

However, it was noted that level of education is a strong factor to adherence of the ARV for women in Lilongwe as the bivariate analysis showed a p-value of $0.004(\mathrm{p}<0.05)$ at $95 \%$ confidence interval.

Furthermore, the next of kin for the women who were on ARV showed the p-value of 0.051 in a bivariate analysis using Pearson Correlation Coefficient. This suggests that women's adherence to ARV is influenced by the type of the next of kin. These people indeed could help keep reminding the women on the need for refill at the clinic or getting treatment for the ARV side effects.

Table 1 also shows the relationship between knowledge and adherence/non-adherence to ART. It was noted that women who also use the immune boosters are adhering to ART effectively $96.4 \%$ (54) than those not using the boosters. This suggests that these women perceive the importance and benefits of using the ART and are having positive outcome. Moreover, the women who adhered to ART had adequate knowledge that these drug are taken for life.

Table 2 reveals that almost all participants of different age ranges $(82.2 \%)$ said that their general health status improved after ART initiation. However, some participants $(17.8 \%)$ did not see any improvement. This was due to the time they started ART that it was short for them to notice any improvement or due to side effects experienced in the course of taking ART.

Participants who were stable in marriage (98.3\%) experienced an improvement in their general health status after taking the ARVs for more than three years. However, those women who reported of not improved much are the ones who got divorced $(27.8 \%)$ which is the highest number to show that they did not improve.

A remarkable increase in the education was also seen in those who went to primary $(97.9 \%, \mathrm{n}=47)$ and secondary $(100 \%, n=26)$ schools. These participants noted their health status improving. It also indicated that women who are educated up to the secondary level could perceive health status improvement while taking the ARVs. On the other hand, $33.3 \%$ of participants who never attended school did not see any improvement.
Table 1. Relationship of art adherence and perceived knowledge $n=118$.

\begin{tabular}{|c|c|c|c|c|}
\hline \multicolumn{2}{|c|}{ Variables } & \multicolumn{3}{|c|}{$\begin{array}{c}\text { Do you } \\
\text { adhere to art? }\end{array}$} \\
\hline Knowledge level & Values & Yes & No & P-Value \\
\hline \multirow{5}{*}{ Marital status } & Married & 58 & 6 & \multirow{5}{*}{0.016} \\
\hline & Single & 14 & 1 & \\
\hline & Divorced & 16 & 2 & \\
\hline & Separated & 58 & 6 & \\
\hline & Widowed & 5 & 0 & \\
\hline \multirow{3}{*}{ Religion } & Christian & 78 & 9 & \multirow{3}{*}{ - } \\
\hline & Muslim & 21 & 1 & \\
\hline & Other & 8 & 1 & \\
\hline \multirow{4}{*}{ Level of education } & Never attended & 20 & 6 & \multirow{4}{*}{0.004} \\
\hline & Primary & 51 & 3 & \\
\hline & Secondary & 28 & 1 & \\
\hline & College/university & 8 & 1 & \\
\hline \multirow{5}{*}{ Next of kin } & Parents & 8 & 1 & \multirow{5}{*}{0.0012} \\
\hline & Husband & 54 & 4 & \\
\hline & Children & 35 & 3 & \\
\hline & Others & 10 & 3 & \\
\hline & Parents & 8 & 1 & \\
\hline \multirow{3}{*}{ ART knowledge } & Lifelong drugs & 51 & 9 & \multirow{3}{*}{0.311} \\
\hline & Immunity boosters & 54 & 2 & \\
\hline & Not sure & 2 & 0 & \\
\hline \multirow{3}{*}{ Source of information } & Hospital & 97 & 11 & \multirow{3}{*}{0.002} \\
\hline & Friends & 3 & 0 & \\
\hline & Radio & 7 & 0 & \\
\hline \multirow{3}{*}{$\begin{array}{l}\text { Adherence } \\
\text { knowledge }\end{array}$} & $\begin{array}{l}\text { Following } \\
\text { prescription }\end{array}$ & 88 & 10 & \multirow{3}{*}{ - } \\
\hline & $\begin{array}{l}\text { You don't become } \\
\text { sick anyhow }\end{array}$ & 15 & 0 & \\
\hline & $\begin{array}{l}\text { Prevents drug } \\
\text { resistance }\end{array}$ & 4 & 1 & \\
\hline \multirow{5}{*}{$\begin{array}{l}\text { Adherence } \\
\text { knowledge time }\end{array}$} & When pills remain $<8$ & 27 & 2 & \multirow{5}{*}{0.004} \\
\hline & $\begin{array}{l}\text { When not sick } \\
\text { more often }\end{array}$ & 40 & 2 & \\
\hline & When CD4 is $<250$ & 3 & 0 & \\
\hline & When no pills remain & 24 & 2 & \\
\hline & $\begin{array}{l}\text { When I fulfill } \\
\text { appointments }\end{array}$ & 13 & 5 & \\
\hline \multirow{5}{*}{$\begin{array}{l}\text { Non-adherence } \\
\text { knowledge time }\end{array}$} & When pills remain $>8$ & 25 & 1 & \multirow{5}{*}{0.021} \\
\hline & When CD4 $<250$ & 12 & 0 & \\
\hline & $\begin{array}{l}\text { When I skip days } \\
\text { without taking drugs }\end{array}$ & 13 & 4 & \\
\hline & Frequent illnesses & 48 & 6 & \\
\hline & Don't know & 9 & 0 & \\
\hline
\end{tabular}


in Lilongwe Urban Health Centres, Malawi

Table 2. Relationship of general health status and demographic variables $n=118$.

\begin{tabular}{|c|c|c|c|c|c|c|c|c|c|}
\hline \multirow[b]{2}{*}{ Demographic data } & \multirow[b]{2}{*}{ Co-Variates } & \multicolumn{8}{|c|}{ General health status since art initiation? } \\
\hline & & \multicolumn{2}{|c|}{ Improved } & \multirow[t]{2}{*}{ P-Value } & \multicolumn{2}{|c|}{ Not improved } & \multirow[t]{2}{*}{ P-Value } & \multicolumn{2}{|c|}{ Total } \\
\hline \multirow{5}{*}{ Age } & $15-25 \mathrm{yrs}$ & 21 & $91.3 \%$ & & 2 & $8.7 \%$ & & 23 & $100 \%$ \\
\hline & $26-35$ yrs & 44 & $95.7 \%$ & \multirow{4}{*}{0.346} & 2 & $4.3 \%$ & \multirow{4}{*}{0.048} & 46 & $100 \%$ \\
\hline & $36-45 \mathrm{yrs}$ & 20 & $95.2 \%$ & & 1 & $4.8 \%$ & & 21 & $100 \%$ \\
\hline & $46-55$ yrs & 8 & $72.7 \%$ & & 3 & $27.3 \%$ & & 11 & $100 \%$ \\
\hline & $56-65 \mathrm{yrs}$ & 4 & $66.7 \%$ & & 2 & $31.3 \%$ & & 6 & $100 \%$ \\
\hline \multirow{5}{*}{ Tribe } & Chewa & 38 & $90.5 \%$ & \multirow{5}{*}{0.251} & 4 & $9.5 \%$ & \multirow{5}{*}{0.349} & 42 & $100 \%$ \\
\hline & Tumbuka & 12 & $85.7 \%$ & & 2 & $14.3 \%$ & & 14 & $100 \%$ \\
\hline & Yao & 15 & $100 \%$ & & 0 & $0.0 \%$ & & 15 & $100 \%$ \\
\hline & Ngoni & 18 & $81.8 \%$ & & 4 & $18.2 \%$ & & 22 & $100 \%$ \\
\hline & Other & 14 & $100 \%$ & & 0 & $.0 \%$ & & 14 & $100 \%$ \\
\hline \multirow{5}{*}{ Marital status } & Married & 58 & $98.3 \%$ & \multirow{5}{*}{0.016} & 1 & $1.7 \%$ & \multirow{5}{*}{0.578} & 59 & $100 \%$ \\
\hline & Single & 14 & $100 \%$ & & 0 & $0.0 \%$ & & 14 & $100 \%$ \\
\hline & Divorced & 13 & $72.2 \%$ & & 5 & $27.8 \%$ & & 18 & $100 \%$ \\
\hline & Separated & 11 & $78.6 \%$ & & 3 & $21.4 \%$ & & 14 & $100 \%$ \\
\hline & Widowed & 1 & $50 \%$ & & 1 & $50 \%$ & & 2 & $100 \%$ \\
\hline \multirow{3}{*}{ Religion } & Christian & 70 & $89.7 \%$ & \multirow{3}{*}{0.391} & 8 & $10.7 \%$ & \multirow{3}{*}{0.032} & 78 & $100 \%$ \\
\hline & Muslim & 20 & $100 \%$ & & 0 & $0.0 \%$ & & 20 & $100 \%$ \\
\hline & Other & 7 & $77.8 \%$ & & 2 & $22.2 \%$ & & 9 & $100 \%$ \\
\hline \multirow{4}{*}{ Level of education } & Never attended & 16 & $66.7 \%$ & \multirow{4}{*}{0.004} & 8 & $33.3 \%$ & \multirow{4}{*}{0.004} & 24 & $100 \%$ \\
\hline & Primary & 47 & $97.9 \%$ & & 1 & $2.1 \%$ & & 48 & $100 \%$ \\
\hline & Secondary & 26 & $100 \%$ & & 0 & $0.0 \%$ & & 26 & $100 \%$ \\
\hline & College/university & 8 & $88.9 \%$ & & 1 & $11.1 \%$ & & 9 & $100 \%$ \\
\hline \multirow{3}{*}{ Occupation } & Business & 50 & $94.3 \%$ & \multirow{3}{*}{0.001} & 3 & $5.7 \%$ & & 53 & $100 \%$ \\
\hline & Teacher & 9 & $100 \%$ & & 0 & $0.0 \%$ & - & 9 & $100 \%$ \\
\hline & Medical personnel & 3 & $75 \%$ & & 1 & $25 \%$ & & 4 & $100 \%$ \\
\hline
\end{tabular}

Therefore, education was perceived as a major factor for ART adherence and it matters more for women's health on ART.

It was also revealed that those women who do business adhere to ART more than those with different occupations. This is so because they are self-governed on the time they are to go for refill as compared to those who are employed by other people or are not working. If these people have high adherence rates, then they have adequate knowledge on adherence.

When bivariate analysis was used in the analysis, we could not reject the null hypothesis that women who depended on the hospital as source of information were associated with the ART adherence, the p-value of the two tailed t-test was $0.002(p<0.05)$ at $95 \%$ confidence interval.

It was also noted that peripheral neuropathy is the commonest side effect for those women who are adhering to the ART (see Table 2). But most of the women had been experiencing such side effects at the beginning of the ART. However, we rejected the null hypothesis that peripheral neuropathy is associated with ART adherence 
as the two tailed t-test was $0.234(\mathrm{p}<0.05)$.

It was also found out that marital status is highly associated with women's health status on ARV, p-value was $0.016(\mathrm{p}<0.05)$. This suggests that women who were married were effectively motivated to continue treatment by their spouses. Furthermore in Table 2, level of education was highly associated with the general health status of the women on ART as the two tailed t-test revealed $\mathrm{p}$-value of $0.004(\mathrm{p}<0.05)$.

We could not also reject the null hypothesis that type of occupation is strongly associated with the women's general health status on ART as the two tailed t-test showed p-value of $0.001(\mathrm{p}<0.05)$.

In the logistic regression Table 3 above, the mean of summative knowledge variables 56.9 was used as the cut point for the construction of the model. Different ordinal variables were executed into the model to associate with the women's general health status as the independent ordinal variable at $95 \%$ confidence internal and a predictive alpha level of 0.05 .

Use of lifelong drug by women on ARV was found to be high associated with general health status in the logis- tic regression model as the $\mathrm{OR} \leq 3.49$; $\mathrm{CI}(1.59 \pm 6.36)$; $\mathrm{p}(0.001)$ (see Table 3). This means that women who had had a chance to take lifelong drugs before found it easy to follow the instruction of the ARV when initiated as they had been using other drugs before thereby their health improved tremendously.

It should also be pointed out that women's source of health, on related information from the hospital was highly associated with their general health status since the OR $\leq 2.89$; CI $(1.66 \pm 5.38) ; \mathrm{p}(0.039)$. This indicates that availability of health related information to women at the hospital helps to make their general health status to improve. Therefore, source of information is a strong factor that influence ARV adherence.

When covariate "following prescription" was executed into the logistic regression in Table 3, it was highly associated with women's health status as the $\mathrm{OR} \leq 2.67$; CI $(1.54 \pm 4.66) ; p(0.028)$. This means that all women who were following the prescription of the ARV improved their general health status greatly. So, following prescription has been found to be a strong factor that influence ARV adherence.

Table 3. Logistic regression of women's general health status with their art knowledge level on HIV/AIDS $\mathbf{n}=118$.

\begin{tabular}{|c|c|c|c|c|c|c|c|c|}
\hline \multirow{3}{*}{$\begin{array}{l}\text { Women's knowledge level } \\
\text { ART knowledge }\end{array}$} & \multirow{3}{*}{$\begin{array}{l}\text { Co-Variables } \\
\text { Lifelong drugs }\end{array}$} & \multicolumn{7}{|c|}{ Women's general health status } \\
\hline & & \multicolumn{2}{|c|}{ Improved } & \multicolumn{2}{|c|}{ Not improved } & \multirow{2}{*}{$\frac{\text { Odds ratio }}{3.49}$} & \multirow{2}{*}{$\frac{\mathrm{CI}(95 \%)}{1.59-6.36}$} & \multirow{2}{*}{$\frac{\text { P-Value }}{0.001}$} \\
\hline & & 46 & $85.2 \%$ & 8 & $14.8 \%$ & & & \\
\hline & Immunity boosters & 50 & $98 \%$ & 1 & $2 \%$ & 1.47 & $0.50-4.27$ & 0.476 \\
\hline & Not sure & 1 & $50 \%$ & 1 & $50 \%$ & - & - & - \\
\hline & Hospital & 89 & $90.8 \%$ & 9 & $9.2 \%$ & 2.89 & $1.66-5.38$ & 0.039 \\
\hline \multirow[t]{3}{*}{ Source of information } & Friends & 2 & $100 \%$ & 0 & $0.0 \%$ & 0.35 & $0.15-0.80$ & 0.014 \\
\hline & Radio & 6 & $85.7 \%$ & 1 & $14.3 \%$ & - & - & - \\
\hline & Following prescription & 82 & $92.1 \%$ & 1 & $7.1 \%$ & 2.67 & $1.54-4.66$ & 0.028 \\
\hline \multirow[t]{2}{*}{ Adherence knowledge } & You don't become sick anyhow & 12 & $85.7 \%$ & 2 & $14.3 \%$ & 1.09 & $0.68-2.55$ & 0.393 \\
\hline & Prevents drug resistance & 3 & $75 \%$ & 1 & $25 \%$ & - & - & - \\
\hline \multirow{4}{*}{ Adhere to ART } & Yes & 88 & $91.7 \%$ & 8 & $8.3 \%$ & 6.22 & $1.98-7.31$ & 0.002 \\
\hline & No & 9 & $81.8 \%$ & 2 & $18.2 \%$ & - & - & - \\
\hline & When pills remain $<8$ & 24 & $100 \%$ & 0 & $0.0 \%$ & 3.41 & $1.36-5.92$ & 0.001 \\
\hline & When not sick more often & 34 & $90.2 \%$ & 4 & $9.8 \%$ & 0.48 & $0.10-0.78$ & 0.762 \\
\hline \multirow[t]{5}{*}{ Adherence knowledge time } & When CD4 is $<250$ & 2 & $66.7 \%$ & 1 & $33.3 \%$ & 3.39 & $1.22-3.81$ & 0.031 \\
\hline & When no pills remain & 21 & $87.5 \%$ & 3 & $12.5 \%$ & 0.58 & $0.11-0.64$ & 0.567 \\
\hline & When I fulfill appointments & 13 & $86.7 \%$ & 4 & $13.3 \%$ & - & - & - \\
\hline & When pills remain $>8$ & 18 & $100 \%$ & 0 & $0.0 \%$ & 5.31 & $1.11-3.70$ & 0.034 \\
\hline & When CD4 $<250$ & 10 & $90.9 \%$ & 1 & $9.1 \%$ & 6.19 & $1.37-2.33$ & 0.027 \\
\hline \multirow[t]{3}{*}{ Non-Adherence knowledge time } & $\begin{array}{l}\text { When I skip days } \\
\text { without taking drugs }\end{array}$ & 14 & $87.5 \%$ & 2 & $12.5 \%$ & 0.29 & $0.17-0.89$ & 0.663 \\
\hline & Frequent illnesses & 49 & $92.5 \%$ & 4 & $7.5 \%$ & 0.81 & $0.36-0.98$ & 0.788 \\
\hline & Don't know & 6 & $66.7 \%$ & 3 & $33.3 \%$ & - & - & - \\
\hline
\end{tabular}

This is a logistic model generated after using $95 \%$ cut point for the regression formula. 
Hospital waiting time (see Table 3) was also found to be at board line relationship with ARV adherence as the $\mathrm{p}$-value was 0.052 . This means that the more the waiting time the less likely the women's ARV adherence (see Table 4).

Short waiting time of the women at the hospital during

Table 4. The relationship between women's appointment time and ARV side effects $n=118$.

\begin{tabular}{|c|c|c|c|c|}
\hline \multirow[b]{2}{*}{ Variables } & \multirow[b]{2}{*}{ Covariates } & \multicolumn{3}{|c|}{ Appointed time fulfillment } \\
\hline & & No & Yes & P-Value \\
\hline \multirow{4}{*}{ Hindrances } & Time for work/business & 9 & 2 & \multirow{4}{*}{0.047} \\
\hline & Transport problems & 15 & 1 & \\
\hline & Distance & 3 & 1 & \\
\hline & Illness & 7 & 1 & \\
\hline \multirow{5}{*}{ Hospital waiting time } & $<$ hour & 9 & 33 & \multirow{5}{*}{0.002} \\
\hline & 2 hours & 10 & 25 & \\
\hline & 3 hours & 7 & 8 & \\
\hline & 4 hours & 4 & 11 & \\
\hline & 5 hours \& more & 5 & 6 & \\
\hline \multirow{3}{*}{ Relationship with next of kin } & They encourage & 14 & 29 & \multirow{3}{*}{0.021} \\
\hline & They discriminate & 1 & 3 & \\
\hline & They don't care & 20 & 47 & \\
\hline \multirow{4}{*}{ Other related members on ART } & Husband & 12 & 23 & \multirow{4}{*}{0.530} \\
\hline & Children & 1 & 8 & \\
\hline & Sisters/ brothers & 2 & 4 & \\
\hline & Other & 10 & 28 & \\
\hline \multirow{4}{*}{ Feelings when taking the drug at home } & Ashamed of self & 2 & 7 & \multirow{4}{*}{0.056} \\
\hline & A sinner & 4 & 4 & \\
\hline & Tired & 5 & 2 & \\
\hline & Good & 24 & 70 & \\
\hline \multirow{4}{*}{ Initiation ART period } & $1-6 \mathrm{~m}$ ago & 8 & 20 & \multirow{4}{*}{0.031} \\
\hline & $6-12 \mathrm{~m}$ ago & 16 & 30 & \\
\hline & $2-5$ yrs ago & 8 & 28 & \\
\hline & $6-10$ yrs ago & 3 & 5 & \\
\hline \multirow{5}{*}{ ART side effects } & Nausea/vomiting & 4 & 13 & \multirow{5}{*}{0.432} \\
\hline & Jaundice & 3 & 1 & \\
\hline & Peripheral neuropathy & 14 & 12 & \\
\hline & Rash & 2 & 8 & \\
\hline & Nothing & 12 & 49 & \\
\hline \multirow{4}{*}{ Experienced length of side effects } & At the beginning & 9 & 19 & \multirow{4}{*}{0.058} \\
\hline & Not often & 13 & 11 & \\
\hline & Very often & 3 & 6 & \\
\hline & Daily & 0 & 2 & \\
\hline \multirow{5}{*}{ Physiological ART side effects } & Weight gain & 19 & 35 & \multirow{5}{*}{0.042} \\
\hline & Weight loss & 1 & 6 & \\
\hline & Chronic rash & 5 & 5 & \\
\hline & Lipodystrophy & 3 & 1 & \\
\hline & Other & 7 & 20 & \\
\hline \multirow{2}{*}{$\begin{array}{l}\text { General body status } \\
\text { since the initiation of ART }\end{array}$} & Improved & 26 & 80 & \multirow{2}{*}{0.049} \\
\hline & Not improved & 9 & 2 & \\
\hline
\end{tabular}

This is a bivariate analysis table with. 
the ARV refill period is highly associated with adherence level OR $\leq 4.11$; CI $(2.05 \pm 6.12) ; p(0.021)$. This means that when the women go to the clinic and are seen immediately, could influence them to come back during the next visit without hesitation as a result this influence them to ARV adherence throughout their life.

Furthermore, strong religious beliefs that God has supernatural powers and heals HIV and AIDS has been found to be strongly associated with non adherence to ARV among women in Malawi OR $\leq 5.37$; CI $(3.16 \pm$ 7.36); $\mathrm{p}(0.004)$. This is a pathetic situation to most women who are strong believers. Women even stop taking the ARV once they have been offered a prayer by a local Christian prophet.

Moreover, in table four, fulfilling of appointment was also related to general body status. Those who felt not improved could not meet the appointment but those who felt that they were improving met the appointment as the $\mathrm{p}$-value was found to be $0.049(\mathrm{p}<0.05)$.

The study has revealed that common the main factors that influence adherence are women's side effects that are experienced in the course of taking ART which are nausea and vomiting, generalized rash and peripheral neuropathy. This is similar to the study done by the British Columbia [17], that found out that the effects of ART included, skin rash, nausea and vomiting among others. The study discovered that those who experienced side effects just at the beginning of ART initiations adhered to ART as compared to those who experienced side effects very often that they found it difficult to adhere to ART.

Lipodystrophy and weight loss are also some of the factors noted in this study of which some of the women on ART developed and were causing them not to take the ARVs continuously [17]. These side effects distort their body image that they feel anyone may know that they are on ART and these make them stop adhering to ART. This is in relation to what Reynolds [18] discovered. The study discovered that participants who had lipodystrophy and fat loss as side effects engaged in harmful behaviours in order to control bodily changes. Reynolds [19] also noted that participants feared that weight loss represented disease and worried that visible changes would lead to unintentional disclosure of their HIV status.

The study also revealed that most individuals who fail to fulfill appointments because of traveling long distances to collect ARVs and the majority goes by walking which is tiresome. The findings are similar to what Annelie et al. [20] discovered. Annelie's study found out that financial struggles with ART related costs like transport, food, hindered adherence to ART of which this has been true in this study. The study also found that patients who stayed on the queue for a long time (4 - 5 hours and more) before being helped by the service pro- vider found it difficult to fulfill all appointments as they were thinking of the past experiences encountered at the same health centre [21]. This also makes ART users who also work to not visit the clinic for refill at the appointed time.

The study further revealed that most clients have good relationships with their next of kin and with their service providers that they both encourage and help them accordingly. This helps them get relieved from anxiety and make them feel at home and needed. This is in contradiction to what Klitzman et al. [22,23] discovered that if family members or friends see patients to be taking ART; this conveys a signal that they are HIV positive or living with AIDS. Despite stressful events, the study found out that the majority continue taking ART. This indicates effective coping mechanisms for the women on the ART $[24,25]$. On the other hand, some participants stopped taking ART reasoning that God is superior and will heal them (relies for God's interventions) [26]. Indeed some respondents believed in spiritual healing and abandoned ART in this study which is not good as this could only aggravate or the HIV in the body.

\section{Conclusion}

The study has found out that the main factors that contribute to ART adherence among women are increased knowledge levels on adherence, its importance and consequences for not adhering to ART; Short waiting time; good relationships with the next of kin and service providers; trust and effective coping mechanisms to stressful events. On the other factors that contribute to non-adherence are reduced knowledge level; Side effects of ART; bad relationships with service providers and with the next of kin as well as occupation of the clients. Despite stressful events to HIV positive living women, this study revealed that the majority of these participants would continue taking ART if the factors are very minimal. Encouraging the women who stop taking ART particularly in urban health centres due to such factors like religious beliefs that God is superior and will heal them would influence the ART survival rate in Malawi.

\section{Recommendation}

There is need to review the policy and evaluate their previous policy on HIV and ART thereby adding some information with the aim of addressing the problems identified in this study. There is need to improve service providers relationship with clients this will help to identify their problems in the course of rendering care to client who are on ART. The researcher recommends that ART service providers should be starting as earlier as possible to assist clients so as to minimize waiting time by the 
clients so as to improve adherence to ART.

\section{REFERENCES}

[1] I. Anneli, "Adherence of Immune Booster among HIV Positive People in India," Journal of Emerging Investigators, Vol. 103, No. 6, 2007, pp. 594-610.

[2] E. Araaj, "Factors Affecting Adherence of Persons Living with HIV to Antiretroviral Therapy in Lebanon," Operational Research in Tropical and Other Communicable Diseases: Final Report Summaries, Vol. 173, No. 20072008, 2005, p. 32.

[3] D. Bandyopadhyay, A. K. Basu, S. K. Mandal, R. Bandyopadhyay, S. K. Pal, P. P. Chakraborty and S. Bose, "Glycaemic Consequences of HIV and Highly Active Antiretroviral Therapy: A Pilot Study and Review of Literature," Journal of Indian Medical Association, Vol. 102, No. 8, 2004, pp. 453-456.

[4] British Columbia on Person with AIDS Society, "AntiRetroviral Therapy in Women," Columbia, 2010.

[5] N. Burns and S. Grove, "The Practice of Nursing Research: Conduct, Critique and Utilization," 5th Edition, Elsevier Saunders Publication Ltd., St Louis, 2005.

[6] M. Chesney, "Adherence to Highly Active Antiretroviral Therapy Regimens," AIDS Patient Care and STDs, Vol. 17, No. 4, 2003, pp. 169-177. doi:10.1089/108729103321619773

[7] M. J. Clark, "Community Health Nursing: Advocacy for Population Health," 5th Edition, Pearson Prentice Hall, Upper Saddle River, 2008.

[8] M. B. Cauldbeck, et al., "Adherence to Antiretroviral Therapy among HIV Patients in Bangalore," AIDS Research and Therapy, Vol. 10, No. 6, 2009, pp. 6-7.

[9] History of HIV \& AIDS in Malawi, 2007. www.avert.org

[10] A. Kagee, "Adherence to Antiretroviral Therapy in the Context of the National Roll-Out in South Africa: Defining a Research Agenda for Psychology," South African Journal of Psychology, Vol. 38, No. 2, 2006, pp. 413-428.

[11] R. L. Klitzman, et al., "Intricacies and Inter-Relationships between HIV Disclosure and HAART: A Qualitative Study," AIDS Care, Vol. 16, No. 5, 2004, pp. 628-640. doi:10.1080/09540120410001716423

[12] H. Madaki, "Factors that Facilitate and Constrain Adherence to ARV Drugs among Adults at Four Public Health Facilities in Botswana: A Pre-Intervention Study Feedback to Serowe Study," Botswana, 2009.

[13] M. Massaquoi, et al., "Patient Retention and Attrition on Anti-Retroviral Treatment at District Level in Rural Malawi," Transactions of the Royal Society of Tropical Me- dicine and Hygiene, Vol. 103, No. 6, 2009, pp. 594-600. doi:10.1016/j.trstmh.2009.02.012

[14] N. H. Miller, "Compliance with Treatment Regimens in Chronic Asymptomatic Diseases," The American Journal of Medicine, Vol. 102, No. 2, 1997, pp. 43-49. doi:10.1016/S0002-9343(97)00467-1

[15] MOH \& NAC, “Treatment of AIDS: Guidelines for the Use of ART in Malawi," 3rd Edition, NAC, Lilongwe, 2008.

[16] H. Calverton and K. Marryland, "Malawi Demographic and Health Survey," National Statistical Office (NSO), 2004. www.nsomalawi.mw

[17] A. W. Nyambura, "Factors that Influence Non-Adherence to Antiretroviral Therapy among HIV and AIDS Patients in Central Province," Kenya, 2009.

[18] D. F. Polit and C. T. Beck, "Essentials of Nursing Research: Methods, Appraisal and Utilization," 6th Edition, Williams \& Wilkins Company, Philadelphia, 2006.

[19] N. R. Reynolds, et al., "Balancing Disfigurement and Fear of Disease Progression: Patient Perceptions of HIV Body Fat Redistribution," AIDS Care, Vol. 18, No. 7, 2006, pp. 663-673. doi:10.1080/09540120500287051

[20] M. B. Cauldbec, C. O’Connor, M. B. O’Connor, J. A. Saunders, B. Rao, V. G. Mallesh, N. K. P. Kumar, G. Mamtha, C. McGoldrick, R. B. S. Laing and K. S. Satish, "Antiretroviral Therapy Treatment Adherence and Its Determinants in Sub-Saharan Africa: A Prospective at Yaound Cental Hospital, Cameroon," AIDS Research and Therapy, Vol. 6, No. 7, 2009, pp. 64-67.

[21] L. N. Schonnesson, et al., "Baseline Predictors of Three Types of Antiretroviral Therapy (ART) Adherence: A Two Year Follow-Up," AIDS Care, Vol. 18, No. 3, 2006, pp. 246-253. doi:10.1080/09540120500456631

[22] J. M. Suvelius, A. Carrico and M. O. Johnson, “Antiretroviral Therapy Adherence among Transgender Women Living with HIV," Journal of the Association of Nurses in AIDS Care, Vol. 21, No. 3, 2010, pp. 246-256.

[23] N. C. Talam, "Factors Affecting Antiretroviral Drug Adherence among HIV/AIDS Adult Patients Attending HIV/AIDS Clinic at Moi Teaching and Referral Hospital, Eldoret, Kenya," East African Journal of Public health, Vol. 5, No. 2, 2008, pp. 74-78.

[24] Y. R. G. White, "Adherence to ARV Drug Therapy in Children with HIV/AIDS in Jamaica," West Indian Medical Journal, Vol. 57, No. 3, 2008, pp. 56-67.

[25] WHO, "Adherence of ART Report," African Region Report, Central Africa, 2009.

[26] UNIAIDS, "Global Summary of HIV/AIDS Epidemics," Geneva, 2008. 